University of Massachusetts Amherst

ScholarWorks@UMass Amherst

Chemistry Department Faculty Publication Series

Chemistry

1997

\title{
Determination of Se in urine by flow injection hydride generation electrothermal atomic absorption spectrometry with in-atomizer trapping
}

JF Tyson

NG Sundin

CP Hanna

SA McIntosh

Follow this and additional works at: https://scholarworks.umass.edu/chem_faculty_pubs

Part of the Chemistry Commons

\section{Recommended Citation}

Tyson, JF; Sundin, NG; Hanna, CP; and McIntosh, SA, "Determination of Se in urine by flow injection hydride generation electrothermal atomic absorption spectrometry with in-atomizer trapping" (1997). SPECTROCHIMICA ACTA PART B-ATOMIC SPECTROSCOPY. 1069.

Retrieved from https://scholarworks.umass.edu/chem_faculty_pubs/1069 


\title{
Determination of Se in urine by flow injection hydride generation electrothermal atomic absorption spectrometry with in-atomizer trapping
}

\author{
Julian F. Tyson ${ }^{\mathrm{a}, *}$, Nils G. Sundin ${ }^{\mathrm{a}}$, Christopher P. Hanna ${ }^{\mathrm{b}}$, Susan A. McIntosh ${ }^{\mathrm{b}}$ \\ ${ }^{a}$ Department of Chemistry, University of Massachusetts, Box 34510, Amherst, MA 01003-4510, USA \\ ${ }^{\mathrm{b}}$ The Perkin-Elmer Corporation, 761 Main Avenue, Norwalk, CT 06859, USA
}

Received 10 February 1997; accepted 30 May 1997

\begin{abstract}
Following digestion of the sample in a mixture of bromate and hydrobromic acid, the inorganic selenium produced was quantified by trapping hydrogen selenide, formed when a $500 \mu \mathrm{l}$ sample volume injected into a hydrochloric acid carrier stream merged with a stream of sodium borohydride solution, on the iridium-pretreated interior of a graphite furnace atomizer. A number of parameters relating to the digestion, flow injection manifold and trapping in the atomizer were investigated, including a study of factors affecting the detection limit. It was found necessary to heat the digest under reflux at a temperature of $150^{\circ} \mathrm{C}$ for $2 \mathrm{~h}$. Quantitative recoveries, from a human urine matrix, of selenite, selenate, trimethylselenium, selenocystine, selenopurine and selenomethionine spikes were obtained. The efficiency of hydride generation, transport and trapping was $75 \%$. The major factors affecting the detection limit were the reagent purity and the volume injected. For high-purity hydrobromic acid and borohydride free of caking agent, the detection limit, based on three times the standard deviation of the blank, was $0.06 \mu \mathrm{g} 1^{-1}$ for a $1000 \mu \mathrm{l}$ injection volume corresponding to a detection limit of $3 \mu \mathrm{g} 1^{-1}$ for a urine sample. The method was validated by the accurate analyses of Standard Reference Material 2670 from the National Institute of Standards and Technology, and urine samples from an interlaboratory comparison program. The procedure avoids the need for perchloric acid and produces selenium in the +4 oxidation state and thus no reduction is needed prior to generation of the hydrogen selenide. The use of a graphite furnace atomizer avoids the need for frequent reconditioning of the atomizer surface and the need for the standard additions method, both of which are drawbacks of procedures which make use of the quartz tube atomizer. All sample handling procedures following the digestion were automated by the use of flow injection technology.
\end{abstract}

Keywords: Se; Urine; Hydride generation; Flow injection; Graphite furnace; In-situ trapping; Bromine digestion

\section{Introduction}

Recently there has been an increased interest in the essential trace element selenium. This is because of its possible role as a substance with anti-cancer properties and its ability to prevent heart disease

\footnotetext{
* Author to whom correspondence should be addressed.
}

[1,2]. However, there has been a sustained interest in the biochemistry of selenium over several decades with consequent requirements for reliable analytical methods for the determination of both total selenium and various selenium species in biological materials and in the environmental samples which, in many instances, act as the sources of dietary selenium. 
Analysis of urine is a widely used method in assessing selenium metabolism. Information on the mass balance between ingested and excreted selenium can be obtained, as selenium is excreted primarily through urine [3,4] except in cases of acute exposure [1] and urine samples are relatively easy to obtain. In 1984, Robberecht and Deelstra, in a review of the determination of selenium in urine [1] wrote that "fluorimetric (sic) analysis is the most commonly applied technique for selenium determination in urine samples... the procedure used for decomposition of the samples has to be checked carefully to prevent volatilization losses and to obtain the complete destruction of $\mathrm{TMSe}^{+}$, (trimethylselenonium ion) a major selenium metabolite in urine." By 1993, the situation had changed to the extent that Johannessen et al. [5] wrote "Electrothermal atomic absorption absorption spectrometry (ETAAS) using Zeemaneffect background correction is one of the most widely used methods (sic) for the determination of selenium in body fluids" However, Dauchy et al. indicated, [6] in a 1994 review of speciation of selenium in environmental and biological materials, that the most commonly used techniques for the determination of total selenium are gas chromatography, voltammetry and hydride generation atomic absorption spectrometry (HGAAS).

In principle ETAAS would be the technique of choice. The characteristic mass of Se is around 25$35 \mathrm{pg}[5,7,8]$ leading to estimates of detection limit values of about $1 \mu \mathrm{g} \mathrm{l}^{-1}$ in the solution introduced into the furnace. This would appear to be adequate for the determination of selenium in urine, as the lowest value in the range normally encountered is around $10 \mu \mathrm{g}^{-1}$ [1]. However, it is clear from the recent literature that there are problems with methods which use ETAAS as the instrumental technique. These problems arise because (a) selenium exists in several different chemical forms in urine, each of which has different thermal stabilization characteristics [9], (b) whatever form of selenium is introduced into the furnace, it is relatively easy to lose selenium as a volatile species during thermal pretreatment, and (c) urine contains several matrix components that interfere in the measurement, such as sulfate, phosphate and iron.

Several groups of workers have reported recently on the problems arising from the different chemical forms of selenium, and the difficulty of selecting a chemical modifier that is effective in conferring thermal stability on the selenium from each of the different sources $[5,7,10]$. The results of these studies were not particularly encouraging. Laborda et al. reported [7] a method with a detection limit of $21 \mu \mathrm{g}^{-1}$ and Johannessen et al. devised [5] a method in which the urine $(10 \mu \mathrm{l})$ and modifier solution $(5 \mu \mathrm{l})$ were mixed in the furnace and quantification was by the standard additions method. The problems of spectral interferences from phosphate-derived species was considered by Radziuk and Thomassen [11], who concluded that it was very difficult to separate the selenium temporally from the interfering phosphorus-containing species and that this interference is difficult to identify, as exactly matrix-matched blanks are not available. Welz et al. examined [12] the role of sulfate and concluded that sodium sulfate caused analyte losses by expulsion with the violently volatilized matrix early in the atomization stage. For sulfuric acid and magnesium sulfate, the loss mechanism proposed was based on the formation of sulfur oxides which resulted in the formation of volatile selenium dioxide. The proposed remedy was to include barium in the chemical modifier. This suggestion was confirmed by $\mathrm{Ni}$ et al. [13] for use with an instrument with deuterium background correction and by Drake and Hain [14], who devised a procedure for the determination of selenium in urine with a detection limit of $9 \mu \mathrm{g} \mathrm{l}^{-1}$. The procedure used standard additions, peak height measurements and an instrument with deuterium background correction.

For that small group of elements which form volatile hydrides, there is an alternative methodology available for the determination at low concentrations in complex matrices namely hydride generation AAS (HGAAS). The literature on this topic has recently been authoritatively summarized [15]. The technique performed satisfactorily in a recent comparison of methods for the analysis of environmental samples [16]. Until recently, the AA procedure used a quartz tube atomizer. But as this device is prone to problems associated with changes in the atomization conditions and vapor phase interferences from other hydride forming elements, there has been a growing interest in the use of the graphite furnace atomizer. The hydride is collected on the coated interior of the furnace prior to atomization. This procedure was 
first used for a real analysis by Lee in 1982 [17], the most recent determination of selenium is by Hanna et al. [18] and the topic has recently been reviewed by Matusiewicz and Sturgeon [19]. Hydride generation methods have a disadvantage in common with the fluorometric method, namely that all of the selenium must be converted to the same chemical precursor, in this case selenite, prior to detection. As a considerable fraction of the total selenium in urine is present as TMSe, it is necessary to use a decomposition procedure that will oxidatively decompose this compound. It is known that TMSe (and also selenomethionine) are among the organoselenium compounds most resistant to acid attack. Welz and Melcher showed [20] that complete decomposition was possible with a nitric-sulfuric-perchloric acid digestion at $310^{\circ} \mathrm{C}$. This digestion produces selenate, which has to be reduced to selenite prior to the addition of the borohydride reagent. The usual procedure is to heat in the presence of 4-7 $\mathrm{M}$ hydrochloric acid solution for up to $45 \mathrm{~min}$ [21]. This reduction is not without its problems, although it is now recognized that selenium is not lost during this procedure, as was once thought. Low recoveries may be obtained due to "back-oxidation" by the chlorine reaction product [22] The reaction has recently been studied in some detail [23].

A method for the determination of selenium in urine, based on HG with in-atomizer trapping has been developed by $\mathrm{Ni}$ et al. [24]. It was found that $10 \mu \mathrm{g} \mathrm{l}^{-1}$ selenomethionine and selenocystine spikes could be recovered from urine at just over $90 \%$ and that the detection limit, based on peak height measurement, was $20 \mathrm{pg}$ (corresponding to $0.04 \mu \mathrm{g} \mathrm{ml}^{-1}$ in a urine sample). The hydrogen selenide was trapped on a palladium coating on the interior of the graphite furnace. This coating was removed during the atomization stage and had to be replenished prior to each determination. The fate of TMSe in this method was not studied and the calibration procedure was not specified.

Recently, D'Ulivo et al. [25] have shown that bromine in concentrated $\mathrm{HBr}$ can decompose many organoselenium compounds, including TMSe, producing selenite (i.e. the reaction does not oxidize the selenium to the +6 state). Thus, it is possible to use the digest directly (once the excess bromine has been destroyed) in a hydride generation procedure and quantitative recoveries of organoselenium compounds from urine were obtained by a method in which the instrumental techniques was HG atomic florescence spectrometry (HGAFS). This $\mathrm{HBr} / \mathrm{Br}_{2}$ reagent has the potential to replace perchloric acid as the wet digestion method of choice for the determination of total selenium in urine, as it not only decomposes the TMSe ion but converts all of the selenium forms to inorganic selenite $(+4)$, the form necessary for hydride generation determination. A mechanism for the action of this reagent has been proposed [26]. The reagent has also been used [27] as part of a post-column reaction scheme for the determination of selenium compounds by high performance liquid chromatography with atomic spectrometry detection.

The aim of our work was to develop an automated method for the determination of selenium in urine by combining the sample handling benefits of flow injection (reduced sample and reagent consumption, reduced waste generation, and reduced contamination) with the excellent detection limits and freedom from interferences provided by hydride-trapping AAS. The use of the bromine/bromide digestion procedure makes the digestion procedure simpler and safer and hence more accessible to a greater number of laboratories.

The proposed method involves injecting a digested urine sample into a flowing stream of hydrochloric acid solution which is then merged with a stream of sodium borohydride solution. The hydrogen selenide, $\mathrm{H}_{2} \mathrm{Se}$, formed is then stripped from solution by the combined action of the hydrogen produced from the decomposition of the excess borohydride and a merged stream of argon. Following separation of the bulk phases, the gas stream flows through a quartz capillary tube situated in the dosing hole of a heated graphite tube atomizer. The $\mathrm{H}_{2} \mathrm{Se}$ is trapped on the inside of a graphite tube which has been pretreated with iridium $[18,28]$. On heating, the selenium is released, atomized and detected by atomic absorption spectrometry.

\section{Experimental}

\subsection{Apparatus}

A schematic diagram of the apparatus is given in Fig. 1. A flow injection hydride generation manifold 


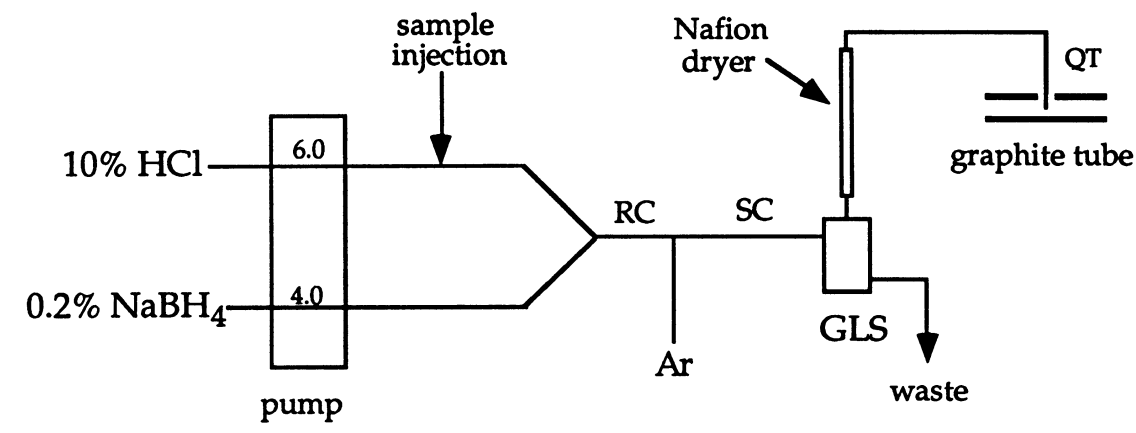

Fig. 1. Schematic diagram of flow injection hydrogen selenide trapping apparatus. RC, reaction coil $12 \mathrm{~cm}$; SC, stripping coil $39 \mathrm{~cm}$; GLS, gasliquid separator; QT, quartz-tipped probe. Flow rates are shown on the pump in $\mathrm{ml} \mathrm{min}^{-1}$. The argon flow rate was $100 \mathrm{ml} \mathrm{min}{ }^{-1}$.

was coupled to a Perkin-Elmer 4100ZL graphite furnace atomic absorption spectrometer and operated with flow injection furnace (FIFU) software version 7.2.1. A Perkin-Elmer FIAS 200 flow injection system was used to operate the hydride generation manifold. This system consisted of two peristaltic pumps, flexible pump tubing, PTFE connecting tubing (0.7 mm i.d.), an injection valve, manifold connectors and an argon carrier gas flow regulator in a single housing. The timing of the valve, speed of the pumps, purge time and data collection were all controlled by Perkin-Elmer software from a Digital DECStation 316sx PC computer. A selenium electrodeless discharge lamp was operated at a current of $260 \mathrm{~mA}$ (a.c.) from a System II power supply (Perkin-Elmer). The spectral bandpass was set at $0.2 \mathrm{~nm}$, a reduced slit height was used and the $196.0 \mathrm{~nm}$ wavelength was monitored. The sample volume injected was $500 \mu \mathrm{l}$ unless otherwise noted. The outlet of the block-type gas liquid separator was passed through a Nafion ${ }^{\circledR}$ dryer tube [29] to remove moisture from the hydrogen/argon/hydride gas mixture before being delivered to the furnace via a quartz tube $(20 \mathrm{~mm} \times 1.3 \mathrm{~mm})$.

\subsection{Reagents}

Stock solutions $\left(100 \mathrm{mg} \mathrm{l}^{-1}\right)$ of seleno-DLmethionine, selenopurine, selenocystine (Sigma) and sodium selenate, $\mathrm{Na}_{2} \mathrm{SeO}_{4}$, (Aldrich) were prepared by dissolving the solid compound in distilled, deionized water produced from an E-pure system (Barnstead). Similarly, a $100 \mathrm{mg} \mathrm{l}^{-1}$ stock solution of trimethylselenonium iodide $\left(\mathrm{CH}_{3}\right)_{3} \mathrm{SeI}$, TMSe,
(Organometallics Inc., E. Hampstead, NH, USA) was prepared. Any experiments requiring selenite solutions were prepared by an appropriate dilution of a $1000 \mathrm{mg} \mathrm{l}^{-1}$ selenium atomic absorption calibration standard (Fisher). For routine use, the flow injection carrier stream solution was prepared by diluting ACS reagent grade $\mathrm{HCl}(37 \% \mathrm{~m} / \mathrm{m}$, Fisher) to a concentration of $10 \%(\mathrm{v} / \mathrm{v})$ with distilled, deionized water. Sodium borohydride, $\mathrm{NaBH}_{4}$, solutions were prepared by dissolving $4.0 \mathrm{~g}$ of the powder (Fisher) in 11 of $0.05 \%$ sodium hydroxide (pellet form, Fisher) and the filtering through a Whatman No. 42 filter paper under suction. All borohydride solutions were prepared fresh daily. A $0.35 \mathrm{M}$ potassium bromate (Fisher) solution was prepared along with a solution of $10 \%(\mathrm{~m} / \mathrm{v})$ hydroxylamine hydrochloride (Aldrich). Concentrated hydrobromic acid, 48\%, (Fisher) was used in conjunction with the potassium bromate solution for sample digestion. Experiments which required low reagent blank values were performed with 99.9999\% pure hydrobromic acid (Alfa Aesar, Johnson Matthey), sub-boiled concentrated $\mathrm{HCl}$ (Seastar, Sidney, B.C., Canada) and sodium borohydride free of anti-caking material (Morton International, Belmont, MA, USA). The coating on the interior of the graphite tube was formed from the thermal treatment of a total of $120 \mu \mathrm{l}$ of $1000 \mathrm{mg} \mathrm{l}^{-1}$ iridium solution as chloride (Perkin-Elmer).

\subsection{Procedure}

The urine samples were digested under reflux conditions in a $50 \mathrm{ml}$ round-bottomed flask attached to a 
Table 1

Furnace program used to pretreat the graphite tube for hydride trapping

\begin{tabular}{llllll}
\hline HGA step No. & Temp. $\left({ }^{\circ} \mathrm{C}\right)$ & Ramp time $(\mathrm{s})$ & Hold time $(\mathrm{s})$ & $\begin{array}{l}\text { Internal argon } \\
\text { flow }\left(\mathrm{ml} \mathrm{min}^{-1}\right)\end{array}$ & Read (s) \\
\hline 1 & 110 & 1 & 40 & 250 \\
2 & 130 & 20 & 50 & 250 & 5 \\
3 & 1200 & 20 & 30 & 250 & 5 \\
4 & 2000 & 1 & 5 & 0 & 5 \\
\hline
\end{tabular}

$30 \mathrm{~cm}$ Liebig condenser ${ }^{1}$. Heat was provided by a silicone oil bath (on a hot plate) whose temperature was monitored by a mercury-in-glass thermometer. A $1.00 \mathrm{ml}$ sample of urine was transferred to the flask along with $10 \mathrm{ml}$ of concentrated hydrobromic acid and $0.5 \mathrm{ml}$ of $0.35 \mathrm{M}$ potassium bromate solution. This mixture was refluxed at a bath temperature of $150 \pm 5^{\circ} \mathrm{C}$ for $2.0 \mathrm{~h}$ If the characteristic red-brown color of bromine was lost during digestion, additional potassium bromate solution was added in $0.1 \mathrm{ml}$ increments. The mixture was allowed to cool to room temperature and then a solution of $10 \%$ hydroxylamine hydrochloride was added dropwise to destroy the excess bromine. This produced a clear or straw colored solution. The digested solution was then diluted to volume in a $50 \mathrm{ml}$ calibrated flask with $10 \%$ hydrochloric acid solution. Blanks were prepared by taking $1 \mathrm{ml}$ of distilled, deionized water through the entire procedure.

The graphite tube was prepared for the trapping of hydrogen selenide by transferring $40 \mu \mathrm{l}$ of $1000 \mathrm{mg}^{-1}$ solution of iridium by micro-pipet followed by heating according to the program in Table 1 . This was repeated until a total of $120 \mu \mathrm{l}$ of the iridium solution had been deposited.

The timing, speed and temperature parameters which govern the movement of the pumps, valve, the furnace autosampler arm and operation of the furnace are given in Table 2 and Table 3. The operation of the FIAS flow injection unit is given in Table 2. First, the FIAS sampling capillary was rinsed with the sample solution while the graphite tube was heated to

\footnotetext{
${ }^{1}$ A Liebig condenser consists of two concentric glass cylinders configured so that hot vapor is condensed on the walls of the inner cylinder by the action of cooling water in the jacket formed by the two cylinders. Condensed vapor runs down the vertically mounted condenser and returns to the reaction vessel.
}

the specified temperature (in this case $250^{\circ} \mathrm{C}$ - see Table 3) for trapping of the hydrogen selenide. Then, in step 1, the sample loop was filled with sample solution. In step 2, the quartz capillary tip was moved into the dosing hole of the graphite furnace, and in step 3, the sample was flushed out of the sample loop and any selenite was converted to $\mathrm{H}_{2} \mathrm{Se}$. The hydrogen selenide was then stripped from solution and, after bulk gas-liquid separation, transported via the Nafion drying tube and the quartz capillary tube to the graphite furnace where it was then trapped on the modified L'Vov platform inside the tube. In step 4, the furnace autosampler arm was returned to its original position so that the quartz pipet tip was no longer inside the dosing hole. In step 5, the furnace program was started. The operation of the furnace is given in Table 3. In step 1, the graphite furnace was purged with argon. In step 2, the collected material was atomized and the absorbance signal measured. In step 3, the graphite furnace was cleaned by a second hightemperature stage.

Calibration standard solutions $(1,2,4,10$ and $15 \mu \mathrm{g}$ $1^{-1}$ ) were prepared fresh daily by dilution of a $1000 \mathrm{mg}$ $1^{-1}$ selenite atomic absorption calibration standard (Fisher). These final calibration standards also contained $10 \% \mathrm{HCl}(\mathrm{v} / \mathrm{v})$. An injection volume of $500 \mu \mathrm{l}$ was used for both sample and standards.

\subsection{Method development}

The effects of a number of relevant parameters were studied. These parameters were divided into two groups: those relating to the operation of the flow injection hydride generation system and graphite furnace, and those relating to the digestion procedure. The figures of merit were sensitivity and percentage recovery, respectively. The role of the volume injected, length of time that the quartz delivery tube 
Table 2

Flow injection (FIAS-200) program

\begin{tabular}{lllll}
\hline Step & Time $(\mathrm{s})$ & Sample pump speed $(\mathrm{rpm})$ & Reagent pump speed (rpm) & Valve \\
\hline Prefill & 10 & 100 & 0 & Fill \\
1 & 20 & 100 & 80 & Fill \\
2 & 8 & 0 & 0 & Inject \\
3 & 30 & 0 & 80 & Inject \\
4 & 8 & 0 & 0 & Inject \\
5 & 5 & 0 & 80 & Fill \\
\hline
\end{tabular}

Note: The sample pump controls the flow of sample solution to the sample loop. The reagent pump controls the flow of acid carrier, borohydride solution and the waste stream. The entry of " 8 " in the time column triggers the insertion (or removal) of the quartz probe into (from) the furnace.

was in the furnace, and the purity of some of the reagents (hydrobromic acid and sodium borohydride) on the detection limit were also studied. The detection limit was calculated as the concentration giving a signal equal to three times the standard deviation of the signal for the blank. A single-cycle univariate search procedure was used. Although, in general, this is not a valid procedure, previous studies [3032] in method development for flow injection chemical vapor generation have shown that there is only limited interaction between the relevant variables and thus acceptable results are obtained by such a univariate search method. The instrumental parameters varied included trapping temperature (over the range $50-300^{\circ} \mathrm{C}$ ), purge gas flow rate (over the range $50-200 \mathrm{ml} \mathrm{min}^{-1}$ ), and atomization temperature (up to $2000^{\circ} \mathrm{C}$ ), as well as the usual flow injection parameters of flow rates, tube lengths, volume injected and so on.

The parameters studied in relation to the digestion included the method of digestion and the temperature. A programmable block digestion unit, as described by D'Ulivo et al. [26], was used to digest urine samples with the same sample size, reagents and heating times as described in the procedure above. In place of the reflux apparatus, the urine samples were contained in

Table 3

Furnace program

\begin{tabular}{lllll}
\hline HGA step & Temp. $\left({ }^{\circ} \mathrm{C}\right)$ & $\begin{array}{l}\text { Ramp time } \\
(\mathrm{s})\end{array}$ & $\begin{array}{l}\text { Hold time } \\
(\mathrm{s})\end{array}$ & Read time (s) \\
\hline 1 & 250 & 1 & 15 & \\
2 & 2000 & 0 & 5 & 5 \\
3 & 2100 & 1 & 3 & \\
\hline
\end{tabular}

individual glass tubes each covered with a watch glass. Digestions under reflux in the $50 \mathrm{ml}$ round bottomed flasks were also performed at a bath temperature of $125 \pm 5^{\circ} \mathrm{C}$, also in accordance with the work of D'Ulivo et al. [26] who indicated that a temperature of $122-126^{\circ} \mathrm{C}$ (the boiling point of concentrated $\mathrm{HBr}$ ) was sufficient to decompose the urinary selenium metabolites.

The overall recovery of the hydride generation and trapping system (a measure of the total efficiency of generating, separating, and transporting the hydride from a liquid carrier stream) was measured. It is defined as the ratio of the characteristic mass obtained from the direct analysis of a liquid solution to the characteristic mass obtained by hydride generation and trapping. In this study the overall recovery was calculated as the ratio of the blank-corrected integrated absorbance obtained by a standard graphite furnace procedure (i.e. by introducing a known volume of solution) from a solution containing $2 \mathrm{ng}$ of selenium to the blank-corrected integrated absorbance signal obtained by the flow injection trapping procedure for a sample volume containing $2 \mathrm{ng}$ of selenium. The signal for $2 \mathrm{ng}$ of selenium is within the linear range of the instrument response function.

\subsection{Method validation}

The ability of the digestion procedure to quantitatively release and convert all the selenium species to selenium(IV) was assessed by recovery studies. In these studies, a human urine sample was first digested and analyzed (by the method described under "procedure" above) to give the "pre-spiked" concentration. Then separate portions of a $1.00 \mathrm{ml}$ human 
urine sample, preserved with $1 \%$ (v/v) nitric acid, were spiked with up to $500 \mathrm{ng}$ of a different selenium compounds (selenite, selenate, selenocystine, selenopurine and selenomethionine and trimethylselenonium, TMSe), chosen as the most likely selenium compounds to be found in urine. Trimethylselenonium ion has been identified as the largest fraction of the total selenium in urine [4]. These spiked samples were digested and analyzed, by the same procedure, to give the "post-spiked" concentrations. Recovery was calculated as the ratio of the concentration determined in a post-spiked sample, corrected for the pre-spiked concentration, to that added. Multiplication by 100 gave the percentage recovery.

A standard reference material from the National Institute of Standards and Technology, NIST, (SRM 2670 freeze-dried urine) and six urine samples from the interlaboratory comparison program (metals in biological samples) of the Centre de Toxicologie du Québec (CHUL) were also analyzed for their selenium content. The NIST SRM 2670 material consists of two materials of different concentrations, the so-called "low level" contains $30 \mu \mathrm{g} \mathrm{l}^{-1}$ and the "elevated level" contains $460 \mu \mathrm{g} \mathrm{l}^{-1}$. The material contains only inorganic selenium forms, while the CHUL samples contain TMSe, selenomethionine, and inorganic selenium.

\section{Results and discussion}

\subsection{Method development}

For digestions performed with the aid of a programmable digestion block, low recoveries (of the order of $50 \%$ ) were obtained. As the solutions did not have the characteristic red-brown color of bromine (seen with the reflux apparatus) the low recoveries could be due to incomplete decomposition of the organoselenium compounds. This may be due to the use of watch glass covers instead of the pear-shaped caps used by D'Ulivo et al. The pear-shaped caps help to retain bromine by providing a surface for condensation. With the reflux apparatus, a temperature of $125 \pm$ $5^{\circ} \mathrm{C}$ was found to be sufficient to decompose and convert the selenium containing amino acids and the inorganic selenium species to a form amenable to hydride generation. However, it was found that for TMSe, the digestion temperature had to be increased to $150 \pm 5^{\circ} \mathrm{C}$ to increase its percentage recovery to above $90 \%$. The recovery of all the other selenium compounds tested remained constant on increasing the temperature.

The reaction coil length (see Fig. 1) chosen was 12 $\mathrm{cm}$, the stripping coil length was $39 \mathrm{~cm}$, the borohydride solution flow rate was $4.0 \mathrm{ml} \mathrm{min}{ }^{-1}$, the hydrochloric acid solution flow rate was $6.0 \mathrm{ml}$ $\mathrm{min}^{-1}$ and the argon flow rate was $100 \mathrm{ml} \mathrm{min}{ }^{-1}$. These values are not significantly different from the values recommended by Perkin-Elmer or from values found in a previous study [29]. Trapping temperature was found not to be a critical factor. The value of $250^{\circ} \mathrm{C}$ was chosen to prevent the condensation of water (or other volatile species) on the interior of the furnace. To obtain the best peak shape, the atomization temperature was set as high as possible without loss of the iridium coating. A value of $2000^{\circ} \mathrm{C}$, with a shorter clean step at $2100^{\circ} \mathrm{C}$, was found to preserve the coating and to be free from memory effects.

In principle, it might be expected that, to achieve lower detection limits, a larger sample size can be injected. However, larger loop volumes require a longer period of time for the sample loop to be completely flushed and so the corresponding reagent blank signal is also larger, as the collection time (time for the quartz tip inside the dosing hole) is now increased. It was found that blank values increased with time, as the sodium borohydride was a major contributor to the blank signal. In order to reduce the reagent contribution to the blank, the quartz probe was positioned inside the dosing hole of the graphite tube only long enough for the sample loop to be flushed and the hydride generated. For the experiments reported here an optimal collection time of $30 \mathrm{~s}$ was employed. Although a significant improvement in detection limit was achieved by using the higher purity hydrobromic acid, the major source of reagent blank was found to be the sodium borohydride. To reduce the blank from this source, granular material rather than the powder form should be used. Typically, the powder contains an anti-caking agent added to the borohydride by each supplier which is a major source of contamination. With the higher purity reagents the detection limit obtained was $0.12 \mu \mathrm{g} \mathrm{l^{-1 }}$ for a $500 \mu \mathrm{l}$ sample and $0.06 \mu \mathrm{g} \mathrm{l^{-1 }}$ for a $1000 \mu \mathrm{l}$ injection loop. Accounting 
Table 4

Recoveries of several selenium-containing compounds from 1.00 $\mathrm{ml}$ of a human urine matrix after the bromine/bromide digestion procedure

\begin{tabular}{lll}
\hline Compound & Selenium added (ng) & \% recovery ${ }^{a}$ \\
\hline Selenite $(\mathrm{Se}(\mathrm{IV}))$ & 500 & $97 \pm 0.6$ \\
Selenate $(\mathrm{Se}(\mathrm{VI}))$ & 500 & $98 \pm 3$ \\
Selenocystine & 500 & $101 \pm 3$ \\
Selenopurine & 500 & $96 \pm 4$ \\
Seleno-DL-methionine & 500 & $95 \pm 2$ \\
TMSe- $\left(\mathrm{CH}_{3}\right)_{3} \mathrm{Se}^{+}$ & 500 & $78 \pm 2$ \\
TMSe- $\left(\mathrm{CH}_{3}\right)_{3} \mathrm{Se}^{+}$ & 150 & $92 \pm 2$ \\
\hline
\end{tabular}

a $95 \%$ confidence interval for $n=3$.

for the 50-fold dilution factor of the digestion procedure, the detection limit for the total selenium in urine was $3 \mu \mathrm{g} \mathrm{l}^{-1}$ for the $1000 \mu \mathrm{l}$ loop and $6 \mu \mathrm{g}^{-1}$ for 500 $\mu$ l. For volumes greater than $1000 \mu 1$, the detection limits were poorer. A study of how to obtain the best detection limit for FI-HG-ETAAS is currently in progress (unpublished results).

The overall recovery, based on the ratio of the signals for $2 \mathrm{ng}$ of selenium, was $75 \%$. This value is in agreement with literature values of $79 \%$ [33] and $82 \%$ [34]

\subsection{Method validation}

The results of the spike and recovery experiments are given in Table 4. Trimethylselenonium ion was the most difficult to recover and it can be seen that improved recoveries were obtained as the amount spiked into the urine matrix was decreased. However, all of the spike amounts exceeded the total selenium content normally found in urine [3] and, as can be
Table 5

Determination of selenium in NIST standard reference material 2670 (toxic metals in urine)

\begin{tabular}{ll}
\hline Certified Se value $^{\text {a }}$ & Measured Se value $^{\text {a }}$ \\
\hline $30 \pm 8 \mathrm{ng} \mathrm{ml}^{-1}$ & $36 \pm 10 \mathrm{ng} \mathrm{ml}^{-1}$ \\
$460 \pm 30 \mathrm{ng} \mathrm{ml}^{-1}$ & $440 \pm 20 \mathrm{ng} \mathrm{ml}^{-1}$ \\
\hline
\end{tabular}

${ }^{\mathrm{a}}$ The \pm terms are $95 \%$ confidence intervals. For the measured values $n=3$.

seen, acceptable recoveries were obtained for all compounds. The recovery of selenate confirms that the digestion procedure produces $\mathrm{Se}(\mathrm{IV})$, as a negligible amount of $\mathrm{H}_{2} \mathrm{Se}$ is generated from $\mathrm{Se}(\mathrm{VI})$. Thus, no further reduction is needed before injecting into the FI manifold and there is a considerable saving in time over methods which require the reduction of $\mathrm{Se}(\mathrm{VI})$ to $\mathrm{Se}(\mathrm{IV})$, as this usually requires heating for many minutes in the presence of concentrated hydrochloric acid.

The results for the analyses of the NIST standard reference materials are given in Table 5, from which it can be seen that, as there is such a large overlap between the $95 \%$ confidence intervals, a t-test would indicate there is no statistically significant difference between the certified values and the measured values. The results for the analyses of the CHUL urine samples are given in Table 6. It can be seen that for only one sample, N9413, is the value found outside the acceptable range. The concentration of selenium in the urine samples from CHUL were not certified for their selenium content by two independent methods, but were calculated on the basis of spiking a known amount of the appropriate solid reagent into a given volume of urine. In addition, neither the shelf-life nor the date of preparation of the CHUL samples are known.

Table 6

Determination of selenium in urine obtained from the interlaboratory comparison program of le Centre de Toxicologie du Québec (CHUL)

\begin{tabular}{lllll}
\hline Sample number & Species & Target value $\left(\mu \mathrm{mol} \mathrm{1}^{-1}\right)$ & Acceptable range & Measured value $^{\text {a }}\left(\mu\right.$ mol 1 $\left.^{-1}\right)$ \\
\hline N9406 & TMSe & 4.30 & $3.95-4.65$ & $4.2_{7} \pm 0.1_{6}$ \\
N9409 & SeMeth & 0.75 & $0.63-0.87$ & $0.6_{7} \pm 0.0_{5}$ \\
N9412 & Se (VI) & 2.90 & $2.64-3.16$ & $2.6_{2} \pm 0.1_{1}$ \\
N9413 & TMSe & 2.40 & $2.17-2.63$ & $2.0_{6} \pm 0.1_{0}$ \\
N9414 & SeMeth & 3.00 & $2.74-3.26$ & $2.6_{4} \pm 0.1_{5}$ \\
N9415 & Se (VI) & 4.00 & $3.67-4.33$ & $3.9_{3} \pm 0.2_{2}$ \\
\hline
\end{tabular}

\footnotetext{
a $95 \%$ confidence interval for $n=3$.

Note: $1.00 \mu \mathrm{mol} \mathrm{l}^{-1}$ is equivalent to $79.0 \mathrm{ng} \mathrm{ml}^{-1}$.
} 


\section{Conclusions}

The method developed has been validated by the accurate determination of selenium in a number of samples, including reference materials and interlaboratory comparison samples. The use of potassium bromate and hydrobromic acid is effective in decomposing a variety of organoselenium compounds, including the trimethylselenonium ion, and produces selenite, the desired precursor for hydrogen selenide generation. A somewhat higher digestion temperature than that previously reported [25] was needed. This procedure is simpler to implement than one in which perchloric acid is used, as the perchloric acid procedure requires (a) specialized fume-hood facilities and (b) removal of the acid followed by reduction of the selenium(VI) to selenium(IV). Flow injection provides a suitable basis for the automation of the procedures following the digestion. Trapping on the interior of a graphite furnace atomizer has several benefits in comparison to the currently used quartz tube atomizers: there is no need for frequent and time-consuming reconditioning of the atomizer surface, there are no vapor phase interferences and it is not necessary to use the method of standard additions. The procedure also has the potential to achieve even lower detection limits through the use of larger sample volumes and purer reagents.

\section{Acknowledgements}

Financial support for this work from the PerkinElmer Corporation, and many helpful discussions with Walter Slavin, Bonaire Technologies, are gratefully acknowledged.

\section{References}

[1] H. J. Robberecht and H. A. Deelstra, Talanta, 31 (1984) 497.

[2] L. Fishbein, Int. J. Environ. and Anal. Chem., 17 (1984) 113.

[3] H. J. Robberecht, H. A. Deelstra, Clin. Chim. Acta, 136 (1984) 107.

[4] M. Janghorbani, B. T. G. Ting, A. Nahapetian and V. R. Young, Anal. Chem., 54 (1982) 1188
[5] J. K. Johannessen, B. Gammelgaard, O. Jons, S. H. Hansen, J. Anal. Atom. Spectrom., 8 (1993) 999.

[6] X. Dauchy, M. Potin-Gautier, A. Astruc, M. Astruc, Fresenius' J. Anal. Chem., 348 (1994) 792.

[7] F. Laborda, J. Vinuales, J. M. Mir, J. R. Castillo, J. Anal. Atom. Spectrom., 8 (1993) 737.

[8] G. R. Carnrick, D. C. Manning, W. Slavin, Analyst, 108 (1983) 1297.

[9] B. Welz, G. Schlemmer, U. Voellkopf, Spectrochim. Acta, Part B, 39 (1984) 501.

[10] H. Docekalova, B. Docekal, J. Kamarek, I. Novotny, J. Anal. Atom. Spectrom., 6 (1991) 661.

[11] B. Radziuk, Y. Thomassen, J. Anal. Atom. Spectrom., 7 (1992) 397.

[12] B. Welz, G. Bozsai, M. Sperling, B. Radziuk, J. Anal. Atom. Spectrom., 7 (1992) 505.

[13] Z.-M. Ni, B. He, H.-B. Han, Spectrochim. Acta, Part B, 49 (1994) 947.

[14] E. N. Drake, T. B. Hain, Anal. Biochem., 220 (1994) 336.

[15] J. Dedina, D. L. Tsalev, Hydride Generation Atomic Absorption Spectrometry, Wiley, Chichester, UK, 1995.

[16] P. M. Haygarth, A. P. Rowland, S. Sturup, K. C. Jones, Analyst, 118 (1993) 1303.

[17] D. S. Lee, Anal. Chem., 54 (1982) 1682.

[18] C. P. Hanna, G. R. Carnrick, S. A. McIntosh, L. C. Guyette and D. E. Bergemann, Atom. Spectrosc., 16 (1995) 82.

[19] H. Matusiewicz and R. E. Sturgeon, Spectrochim. Acta Part B, 51 (1996) 377.

[20] B. Welz, M. Melcher, Anal. Chim. Acta, 165 (1984) 131.

[21] R. M. Olivas, O. F. X. Donard, C. Camara, P. Quevauviller, Anal. Chim. Acta, 286 (1994) 357.

[22] V. Krivan, K. Petrick, B. Welz, M. Melcher, Anal. Chem., 57 (1985) 1703.

[23] S. J. Hill, L. Pitts, P. Worsfold, J. Anal. Atom. Spectrom., 10 (1995) 409.

[24] Z.-M. Ni, B. He, H.-B. Han, Can. J. Appl. Spec., 38 (1993) 11.

[25] A. D'Ulivo, L. Lampugnani, I. Sfetsios, R. Zamboni, Spectrochim. Acta Part B, 48 (1993) 387.

[26] A. D'Ulivo, L. Lampugnani, I. Sfetsios, R. Zamboni, C. Forte, Analyst, 119 (1994) 633.

[27] J. M. Gonzalez Lafuente, M. L. Fernandez Sanchez and A. Sanz-Medel, J. Anal. Atom. Spectrom., 11 (1996) 1163.

[28] Perkin-Elmer, Manufacturer's Instruction Manual, 1993.

[29] N. G. Sundin, J. F. Tyson, S. McIntosh, C. P. Hanna, Spectrochim. Acta Part B, 50 (1995) 369.

[30] S. G. Offley, N. J. Seare, J. F. Tyson, H. A. B. Kibble, J. Anal. Atom. Spectrom., 6 (1991) 133.

[31] J. F. Tyson, S. G. Offley, N. J. Seare, H. A. B. Kibble, C. Fellows, J. Anal. Atom. Spectrom., 7 (1992) 315.

[32] C. P. Hanna, J. F. Tyson, S. G. Offley, Spectrochim. Acta Part B, 47 (1992) 1065.

[33] R. E. Sturgeon, S. N. Willie, G. I. Sproule, P. T. Robinson, S. S. Berman, Spectrochim. Acta Part B, 44 (1989) 667.

[34] R. E. Sturgeon, S. N. Willie, G. I. Sproule, S. S. Berman, J. Anal. Atom. Spectrom., 2 (1987) 719. 